STRUCTURAL

CHEMISTRY

ISSN 2053-2296

\title{
Joel Bernstein: a crystal engineer's crystal engineer
}

\author{
Andreas Lemmerer*¥
}

Molecular Sciences Institute, School of Chemistry, University of the Witwatersrand, Private Bag, PO WITS, 2050, Johannesburg, South Africa. *Correspondence e-mail: andreas.lemmerer@wits.ac.za

Received 28 March 2019

Accepted 28 March 2019

₹ Professor Andreas Lemmerer was a postdoctoral fellow with Joel and co-authored 16 publications, including the last one published in this journal which was in review when Joel passed away.

Keywords: organic solid-state chemistry; polymorphism; crystal engineering; graph sets; hydrogen bonding.

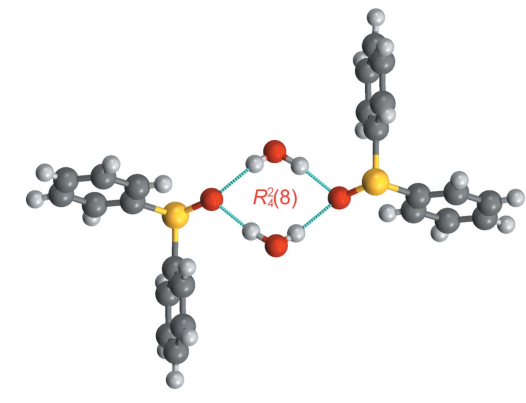

C 2019 International Union of Crystallography
Joel was a gentle giant in the field of organic solid-state chemistry and a person who inspired anyone who was in his presence and attended his charismatic lectures over the five decades of his academic career. To use one of his favourite expressions, he was 'the cat's meow'.

Joel's first publication concerned 'The infrared absorption of normal and ${ }^{18} \mathrm{O}-$ labelled triphenylarsine oxide', published in 1964 (Bernstein et al., 1964). Six years thereafter, he continued with investigations of organic molecules and their electronic properties in 'Absorption and fluorescence spectra of crystalline trans-stilbene' (Bernstein \& Anex, 1970). Interestingly (a word his first Postdoctoral supervisor abhorred), his foray into cocrystals started in 1971 with 'The crystal structure of the 1:1 complex of [3.3]paracyclophane with tetracyanoethylene'. In those days, the term cocrystals had not been used, but the complex reported, a charge-transfer compound, would fall under the umbrella term of cocrystals.

A crucial year was in 1972 when two publications that foretold his main scientific interest were published. From his postdoctoral time with Professor Gerhard Schmidt, whom the solid-state organic chemistry community considers one of the first adopters of the term crystal engineering, the word polymorphism first appeared in one of his publications, 'Conformational studies. Part III. The crystal and molecular structure of 2,4dichlorobenzylideneaniline', published in the Journal of the Chemical Society: Perkin Transactions II (Bernstein, 1972). A second publication, immediately following on in the same issue, was co-authored with Schmidt, i.e. 'Conformational studies. Part IV. The crystal and molecular structure of the metastable form of $N$-( $p$-chlorobenzylidene)- $p$ chloroaniline, a planar anil' (Bernstein \& Schmidt, 1972). In later years, polymorphism has been frequently subdivided into packing polymorphism [which is essentially what polymorphism is as defined by Walter McCrone (McCrone, 1965)], conformational polymorphism and synthon polymorphism. The year 1972 was productive for Joel and resulted in seven publications. The Israeli Crystallographic Community, spearheaded by Schmidt, contributed two pioneers to the field of organic solid-state chemistry, and featured Bernstein as a collaborator. With Professor Leslie Leiserowitz, they published a paper on the crystal and molecular structure of trans, trans-muconic acid (Leiserowitz, 1976). Part of this work was featured in the seminal paper by Leiserowitz on the packing modes of carboxylic acids. In this work, Leiserowitz first began to show predictability in the packing, and also the types of hydrogen-bonding interactions, observed for the carboxylic acid functional group. This concept of prediction and classification would lead to another of Joel's passions, namely hydrogen bonding, but more on that later. In 1975, Joel collaborated with another giant of the Israeli scientific community, Professor Frank Herbstein, who much later wrote a seminal book on charge-transfer compounds (Herbstein, 2005). Again, the publication 'The crystal structure of the $\pi$-molecular compound pyrene:p-benzoquinone' was an example of the type of charge-transfer compound that Herbstein studied intensely (Bernstein et al., 1976). An early and rare example of a ternary compound, the charge-transfer salt pyridine:1-naphthylamine:picric acid (known as Kofler's Compound), showed how not only two-component complexes but ternary complexes could be made using crystal-engineering principles. In this compound, charge transfer and hydrogen bonding were used as two distinct intermolecular interactions (Bernstein, Regev \& Herbstein, 1980). 'Solid state photooligomerization of an extended chiral bifunctional monomer...' is an example of his foray into solid-state photochemistry, continuing in the tradition of Schmidt (Bernstein, Green, \& Rejto, 1980). 
In 'Molecular conformation and electronic structure. VII. The crystal and molecular structure of the isomorphic system $p$-chloro- $N$-( $p$-methylbenzylidene) aniline and $p$-methyl- $N-(p$ chlorobenzylidene)aniline', he showed another example of how methyl groups and $\mathrm{Cl}$ atoms can be substituted without affecting the crystal structure. In this publication, to the best of the author's knowledge, appears the first reference by Joel himself to crystal engineering, 'This observation raises the possibility of engineering crystal structures of benzylideneanilines ...' (Bar \& Bernstein, 1983). Joel kept his focus on conformational polymorphs, investigating highly polymorphic compounds, such as $N^{\prime}$-2-pyridylsulfonamide (sulfapyridine), which has five forms (Bar \& Bernstein, 1985).

Apart from polymorphism, Joel was associated with the work by Margaret Etter and her novel and groundbreaking work on allowing the crystal engineer to see all the trees in a forest of intermolecular interactions. This landmark work was first hinted at in 'Decoding hydrogen bond patterns. The case of iminodiacetic acid' (Bernstein et al., 1990) and then made widely known in a follow-up publication in Acta Crystallographica Section B in 1990, with 'Graph set analysis of hydrogen-bond patterns in organic crystals' (Etter et al., 1990). This relatively short paper distilled out the essentials of what was to become a crucial part of the lingua franca of crystal engineering. One of the major mergings of his two primary interests occurred in 1994, with 'Polymorphism of L-glutamic acid: decoding the $\alpha-\beta$ phase relationship via graph set analysis' (Bernstein, 1991). This was now showing the usefulness of graph-set analysis in showing relative differences and/or similarities in polymorphic forms and it would be a feature of all his future polymorphism reports. Etter and Joel formed a close scientific relationship right up until her passing in 1992. In Joel, she found the perfect person to further popularize graph sets and this culminated in his landmark paper published in Angewandte Chemie entitled 'Graph-set analysis of hydrogen-bond patterns in organic crystals' (Bernstein et al., 1995). It has been cited thousands of times, even more so than the original 1990 paper. Even though this paper has now been cited many more times than those by Etter, Joel felt comfortable if these publications weren't always cited as it meant, according to him, that it became part of the vernacular of solid-state organic chemistry, so widely known that citing it was not necessary to peers in the community.

Returning to polymorphism, Joel is widely known for highlighting the issue of the reproducibility of obtaining crystal forms. With Jack Dunitz, he gave examples of polymorphs that were isolated previously but then could not be obtained again without drastic measures or with great difficulty (Dunitz \& Bernstein, 1995). Joel would joke that once a more stable form was obtained in his lab, the metastable forms had no chance and just having seeds on your lab coat sleeve would be enough to hinder formation. Nonetheless, Joel's lab was a breeding ground for rampant polymorphism to occur. One example was with his student Mikhail Rafilovich, who isolated four polymorphs of a cocrystal former during an investigation that involved synthesizing cocrystals. The title of the resulting work featured another Joel-ism, 'Serendipity and the polymorphs of benzidine', which he presented at numerous conferences. Even during the postdoctoral stint of the author, three out of six polymorphs of an isoniazid derivative appeared within days of each other (Hean et al., 2015).

Polymorphism in cocrystals was an extension of his passion for polymorphic compounds, just as cocrystals were gaining the attention of the crystal-engineering community. Joel showed that polymorphism was just as prevalent in multicomponent complexes, especially so when the coformers were highly polymorphic themselves (Lemmerer et al., 2011).

An interest of Joel's was scanning the historical literature for instances of polymorphism that were not well understood or had been forgotten about. His primary example was the work by the great German crystallographer P. Groth, whose five volumes were in his library. Examples of historically significant systems which he investigated with numerous coauthors are '2,4-Diaminobenzenesulfonic acid - an old system with some new surprises' (Rubin-Preminger \& Bernstein, 2003), 'Groth's original concomitant polymorphs revisited' (Rafilovich et al., 2005), 'Disappearing and reappearing polymorphs. The case of benzocaine:picric acid' (Henck et al., 2001) and '3-Aminobenzenesulfonic acid: a disappearing polymorph' (Rubin-Preminger \& Bernstein, 2005).

In 1978, Joel's work on conformational polymorphism was the focus of the review article 'Conformational polymorphism: the influence of crystal forces on molecular conformation'. Joel looked at conformational changes and their effects on electronic structure throughout his early career. A number of publications, under the heading of 'Conformational polymorphs' appeared throughout the 1970s and 1980s. Fast forwarding to the new millennium, Joel took advantage of the appearance of Big Data and improved technology in crystal structure determination that enabled the flourishing of the Cambridge Structural Database, and developed and articulated clear ideas on molecular crystals. He partnered with Dr Aurora Cruz-Cabeza to write two extensive review papers touching again on the particulars of conformational polymorphs (Cruz-Cabeza \& Bernstein, 2014) and polymorphism in cocrystals (Cruz-Cabeza et al., 2015). In that sense, the cycle closed on his research career with his sudden passing away on 2nd January 2019.

\section{References}

Bar, I. \& Bernstein, J. (1983). Acta Cryst. B39, 266-272.

Bar, I. \& Bernstein, J. (1985). J. Pharm. Sci. 74, 255-263.

Bernstein, J. (1972). J. Chem. Soc. Perkin Trans. 2, pp. 946-950.

Bernstein, J. (1991). Acta Cryst. B47, 1004-1010.

Bernstein, J. \& Anex, B. G. (1970). J. Phys. C, pp. L137-L139.

Bernstein, J., Davis, R. E., Shimoni, L. \& Chang, N.-L. (1995). Angew. Chem. Int. Ed. Engl. 34, 1555-1573.

Bernstein, J., Etter, M. C. \& MacDonald, J. C. (1990). J. Chem. Soc. Perkin Trans. 2, pp. 695-698.

Bernstein, J., Green, B. S. \& Rejto, M. (1980). J. Am. Chem. Soc. 102, 323-328.

Bernstein, J., Halmann, M., Pinchas, S. \& Samuel, D. (1964). J. Chem. Soc. pp. 821-824.

Bernstein, J., Regev, H. \& Herbstein, F. H. (1980). Acta Cryst. B36, 1170-1175. 


\section{scientific commentaries}

Bernstein, J., Regev, H., Herbstein, F. H., Main, P., Rizvi, S. H., Sasvari, K. \& Turcsanyi, B. (1976). Proc. R. Soc. London Ser. A, 347, 419-434.

Bernstein, J. \& Schmidt, G. M. J. (1972). J. Chem. Soc. Perkin Trans. 2, pp. 951-955.

Cruz-Cabeza, A. J. \& Bernstein, J. (2014). Chem. Rev. 114, 21702191.

Cruz-Cabeza, A. J., Reutzel-Edens, S. M. \& Bernstein, J. (2015). Chem. Soc. Rev. 44, 8619-8635.

Dunitz, J. D. \& Bernstein, J. (1995). Acc. Chem. Res. 28, 193-200.

Etter, M. C., MacDonald, J. C. \& Bernstein, J. (1990). Acta Cryst. B46, 256-262.

Hean, D., Gelbrich, T., Griesser, U. J., Michael, J. P. \& Lemmerer, A. (2015). CrystEngComm, 17, 5143-5153.

Henck, J.-O., Bernstein, J., Ellern, A. \& Boese, R. (2001). J. Am. Chem. Soc. 123, 1834-1841.
Herbstein, F. H. (2005). In Crystalline molecular complexes and compounds: structures and principles. Oxford University Press.

Leiserowitz, L. (1976). Acta Cryst. B32, 775-802.

Lemmerer, A., Bernstein, J., Griesser, U. J., Kahlenberg, V., Többens, D. M., Lapidus, S. H., Stephens, P. W. \& Esterhuysen, C. (2011). Chem. Eur. J. 17, 13445-13460.

McCrone, W. C. (1965). Physics and Chemistry of the Organic Solid State, edited by D. Fox, M. M. Labes \& A. Weissberger, Vol. 2, pp. 725-767. London: Interscience Publishers.

Rafilovich, M., Bernstein, J., Harris, R. K., Apperley, D. C., Karamertzanis, P. G. \& Price, S. L. (2005). Cryst. Growth Des. 5, 2197-2209.

Rubin-Preminger, J. \& Bernstein, J. (2003). Helv. Chim. Acta, 86, 3037-3054.

Rubin-Preminger, J. M. \& Bernstein, J. (2005). Cryst. Growth Des. 5, 1343-1349. 